\title{
Retraction Note: Neuroradiological advances detect abnormal neuroanatomy underlying neuropsychological impairments: the power of PET imaging
}

\author{
Benjamin Jacob Hayempour • Abass Alavi
}

Published online: 9 November 2013

(C) Springer-Verlag Berlin Heidelberg 2013

\section{Retraction Note: Eur J Nucl Med Mol Imaging}

DOI 10.1007/s00259-013-2401-3

This article has been withdrawn at the request of the Editor-inChief of European Journal of Nuclear Medicine and Molecular Imaging owing to the unexplained close similarity of some passages to parts of a previous publication [Rushing SE, Langleben DD. Relative function: Nuclear brain imaging in United States courts. J Psychiatry Law 2011; 39 (winter): 567-93].

The online version of the original article can be found at http://dx.doi.org/ 10.1007/s00259-013-2401-3.

\section{B. J. Hayempour $(\square) \cdot$ A. Alavi}

Institute of Neurological Sciences, Department of Radiology,

Division of Nuclear Medicine, Hospital of the University of

Pennsylvania, 3400 Spruce Street, Philadelphia, PA 19104, USA

e-mail: BenjaminJacob13@gmail.com

A. Alavi

e-mail: abass.alavi@uphs.upenn.edu 